\title{
Vanishing winters in Germany: soil frost dynamics and snow cover trends, and ecological implications
}

\author{
Juergen Kreyling ${ }^{1, *}$, Hugh A. L. Henry ${ }^{2}$ \\ ${ }^{1}$ University of Bayreuth, Biogeography, 95440 Bayreuth, Germany \\ ${ }^{2}$ University of Western Ontario, Biology, London, Ontario N6A 5B7, Canada
}

\begin{abstract}
Current climate models are effective at projecting trends in mean winter temperature; however, other ecologically relevant parameters - such as snow cover and soil frost dynamics - are less well investigated. Changes in these parameters are expected to have strong ecological implications, especially in the temperate zone, where it is uncertain whether snow and soil frost will occur with regularity in the future. We explored trends in days with snow on the ground (snowdays), minimum soil temperature (MST), and number of soil freeze/thaw cycles (FTCs, i.e. changes in sign from negative to positive in any pair of consecutive soil temperature records at $5 \mathrm{~cm}$ depth) at 177 German weather stations for 1950-2000. Future trends were explored by statistical modelling based on climatic and topographic predictors. Snowdays decreased uniformly at a rate of $0.5 \mathrm{~d} \mathrm{yr}^{-1}$ in the recent past. This trend is projected to continue to a point where significant parts of Germany will no longer regularly experience snow cover. MST has increased, and is projected to do so in the future, mainly in southern Germany. FTCs have been decreasing uniformly in the recent past. No evidence for increased FTCs or decreased MST with decreasing insulation due to missing snow cover was found. FTCs are projected to decrease disproportionately in northeastern Germany, where past frequencies were higher. Ecological implications of the significant decrease in the occurrence and magnitude of the climate parameters studied include changes in nutrient cycling, productivity and survival of organisms overwintering at the soil surface. Ecological research is needed, as the effects of diminished winters on ecosystems are not well understood.
\end{abstract}

KEY WORDS: Winter climate change · Winter ecology · Freezing-thawing · Soil freezing · Temperate systems

Resale or republication not permitted without written consent of the publisher

\section{INTRODUCTION}

While climate models consistently predict moderate to large increases in air temperatures in most temperate ecosystems over the next century, air temperature projections can be of limited use to ecologists, who study the responses of vegetation and soil processes to winter climate change in these systems and are most interested in changes in snow cover and soil freezing. Soil freezing is influenced by interactions between air temperature and snow cover, with snow insulating soil from changes in air temperature (Isard \& Schaetzl 1998). Air and soil temperatures can often become decoupled over winter, and it has been hypothesized that reduced snow cover caused by climate warming will increase soil freezing in some temperate regions (Groffman et al. 2001). Extremes, such as minimum temperatures, and thresholds, such as soil frost, are accompanied by much larger uncertainties than mean values in climate models (Randall et al. 2007). They do, however, have important ecological implications, and therefore need to be investigated by a combination of climate models, observations and statistical projections. Regional climate models predict an increase in the snow-free season and in soil temperatures over Europe by the end of the century (Jylha et al. 2007, Mellander et al. 2007). At least for northern latitudes, increases in soil freeze/thaw cycles (FTCs, i.e. changes in sign from negative to positive in any pair of consecutive soil temperature records), are predicted (Vena- 
lainen et al. 2001, Mellander et al. 2007) or have been observed (Henry 2008). A more detailed investigation is, however, necessary at warmer latitudes, where climate change may eventually cause a loss of winter processes associated with freezing (Kreyling 2010).

Overwinter processes can have substantial effects on ecosystems that are seasonally covered with snow, as originally demonstrated for the Arctic (e.g. Clein \& Schimel 1995), but now these concepts have been extended to temperate regions (Campbell et al. 2005). In particular, intense soil freezing can disrupt soil microbial activity (Yanai et al. 2004, Bolter et al. 2005), and damage plant roots (Tierney et al. 2001, Weih \& Karlsson 2002), leading to increased soil nitrogen leaching (Joseph \& Henry 2009), increased soil trace gas losses (Matzner \& Borken 2008), decreased plant productivity, and plant mortality (Schaberg et al. 2008). Freezing can also affect soil physical processes directly by breaking up aggregates (Oztas \& Fayetorbay 2003), and reducing water infiltration (Iwata et al. 2010).

The effects of freezing depend on soil freezing dynamics, as the frequency, duration and rate of freezing modulate the effects of intensity (Elliott \& Henry 2009). Thus, ecosystem responses to FTCs have received considerable attention (Henry 2007). The correlation between warmer winters and an increased number of FTCs has been demonstrated for relatively cold temperate systems (Henry 2008). However, this trend has not been ubiquitous, especially for warmer temperate systems (Sinha \& Cherkauer 2008), where warming can lead to unfrozen soils year round and a complete absence of FTCs. Nevertheless, the transition from systems that will experience increased FTCs in response to warming to those that will experience decreased FTCs has not been studied yet.

Plant and soil responses to FTCs have not been consistent among studies, with numerous examples of very minor to no effects (e.g. Grogan et al. 2004), and even examples where increased FTCs have enhanced plant productivity (Kreyling et al. 2008) and soil nutrient retention (Hentschel et al. 2008). This variation in results from may to some extent originate from differences in freezing responses among soil and vegetation types (Lipson \& Monson 1998, Kreyling et al. 2010), but it also appears that variation in FTC treatments among studies has been an important factor, with studies featuring the most severe freezing treatments typically demonstrating the most extreme results (Henry 2007). While efforts can be made to ensure that the freezing rate and intensity are realistic in soil freezing experiments (Herrmann \& Witter 2002, Ferrick \& Gatto 2005), the selection of realistic FTC scenarios becomes challenging in the context of climate research, because predicted changes in FTC frequency must be extrapolated.
Informed predictions of future changes in snow cover and soil freezing dynamics are required in order to interpret the relevance of FTC treatments in the context of climate change.

We examined soil temperature and snow data from 177 sites in Germany with records ranging from 15 to $60 \mathrm{yr}$ in length to explore how snow cover and soil freezing dynamics have changed over time. We also examined how mean winter air temperature and precipitation have correlated with annual soil FTCs. We predicted that snow cover would have declined in warm years across all sites, with the coldest sites experiencing the greatest number of FTCs and lowest minimum temperatures in warm years, and the warmer sites exhibiting the opposite trend. We also used climatic and topographic site parameters to model annual FTCs and to predict changes in FTCs in response to climate change.

\section{MATERIALS AND METHODS}

\subsection{Weather station data}

Climate data on soil temperature and snow cover were obtained from the German Weather Service (DWD). Although data series exist for 420 stations, only those stations with $>15 \mathrm{yr}$ of continuous data were included in the analyses. This resulted in 177 stations for snow data (28 stations with less than 20 yr coverage, 33 between 21 and $40 \mathrm{yr}$, and 116 between 41 and $60 \mathrm{yr}$ ) and 146 stations for soil temperature (74 stations with less than 20 yr coverage, 48 between 21 and 40 yr, and 24 between 41 and $60 \mathrm{yr}$ ). The DWD measures soil temperature and snow depth in plots that are kept free of vegetation in local ambient soil substrate. Snow depth is measured at 07:00 h. Soil temperatures are recorded at $07: 30,14: 30$ and $21: 30 \mathrm{~h}$, with the first 2 corresponding roughly with the daily minimum and maximum soil temperature. Here, temperature readings at $-5 \mathrm{~cm}$ were used.

We defined days with snow on ground (snowdays) by the number of days with at least $1 \mathrm{~cm}$ of snow. Minimum soil temperature (MST) was defined as the absolute minimum temperature in any of the 3 records per d over each winter. FTCs were recorded as the number of changes in sign from negative to positive for any pair of consecutive records in soil temperature data. All 3 parameters (snowdays, MST and FTCs) were recorded per winter, not per calendar year, with the months August to December added to the following calendar year.

Mean winter air temperature was calculated as the mean of the daily mean air temperature (mean of the readings for the 3 records $\mathrm{d}^{-1}$ ) between 1 November 
and 31 March, and was obtained for all stations with free data access (29 weather stations). Ordinary linear least-squares regression was used to determine trends. When applied to the full data set of all stations at once, station identity was introduced as a random factor in linear mixed effect models (Pinheiro \& Bates 2004).

\subsection{Spatial and temporal projections}

Spatial and temporal projections were realized by regression models between the $15 \mathrm{yr}$ mean for each target parameter (i.e. snowdays, MST and FTCs) along with climatic and topographic predictor variables for each station. Climatic predictors for current conditions were taken from the WorldClim dataset (see www. worldclim.org) for the period 1950 to 2000 at a spatial resolution of 2.5' (Hijmans et al. 2005). Derived variables included mean annual temperature, mean winter temperature, mean temperature of the coldest month, minimum temperature of the coldest month, difference between mean temperature of the coldest and the warmest months, mean annual precipitation sum, mean winter precipitation sum, annual heat-moisture index (mean annual temperature +10$) /($ mean annual precipitation/1000), mean winter precipitation sum, mean diurnal range (mean difference of monthly maximum and minimum temperature), sum of degree days below $0^{\circ} \mathrm{C}$, isothermality (mean diurnal range divided by temperature annual range), and temperature seasonality (mean annual temperature standard deviation). Topographic predictors included altitude, slope, and aspect, which were derived from Shuttle Radar Topography Mission (SRTM) digital elevation data sources (Jarvis et al. 2008).

Generalized linear models (GLM) and boosted regression trees (BRT) (Elith et al. 2008) were used to fit regression models between the observations and the climatic and topographic predictors. Predictor selec- tions were optimized, based on 10-fold cross-validated least-squares correlation and residual mean squared error between observed and predicted values. Best-fit models were subsequently used to spatially predict the target variables at the chosen spatial resolution of 2.5'.

Temporal projections into the future were achieved by the application of the regression models on climatic predictors from the Global Climate Model HadCM3 and SRES-scenario A2 for the time period 2070-2100 and spatial resolution of $2.5^{\prime}$ downloaded from WorldClim, which is statistically downscaled to the chosen spatial resolution.

GLM and BRT regression led to almost identical results concerning model accuracy and the set of predictors. The ranges of the climatic predictors for the future projections, however, do not overlap well with their current ranges. BRT is not well suited for such a situation, as it tends to be too conservative and consequently underestimates changes. The geographical pattern, however, was predicted similarly. Based on this, GLM results are presented here.

\section{RESULTS}

\subsection{Historical trends}

Snowdays have decreased in Germany over the last 60 yr (Fig. 1a). This trend was highly significant, averaged over all stations. Of the 177 stations, 150 showed a negative trend ( $p<0.05$ for 69 stations), and 21 a positive trend ( $p<0.05$ for 1 station). The general decrease has accelerated over the last $15 \mathrm{yr}$, with the slope decreasing from -0.48 to $-0.89 \mathrm{~d} \mathrm{yr}^{-1}$.

Annual MSTs have increased over the last $60 \mathrm{yr}$ (Fig. 1b). Soil temperature observations were only started at several stations in 1992. When the start of the observations is restricted to this date, the slope increases from 0.02 to $0.12^{\circ}{\mathrm{C} \mathrm{yr}^{-1}}^{-1} 18$ stations exhibited
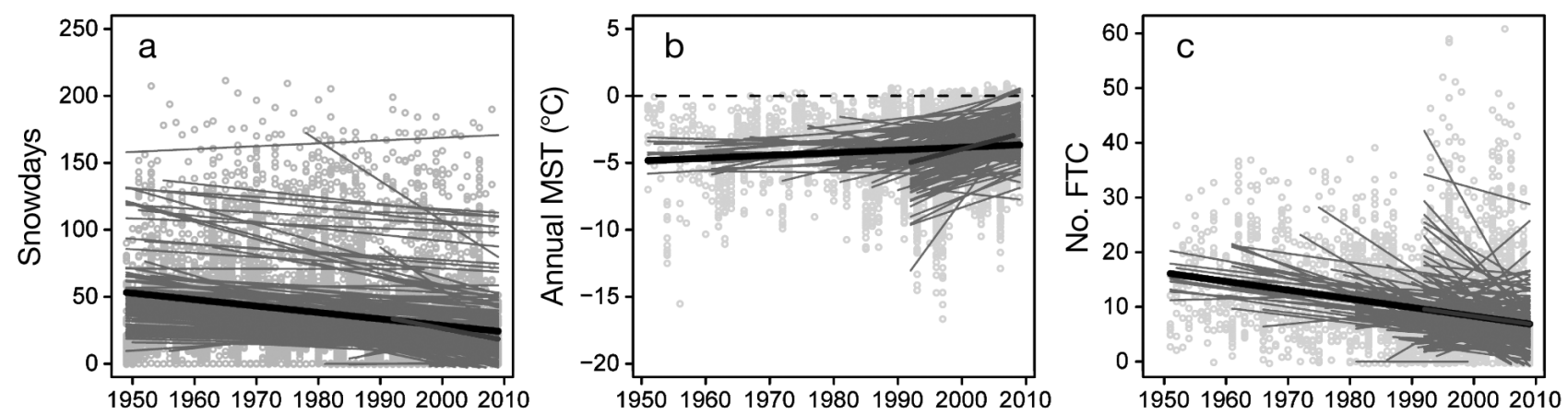

Fig. 1. Temporal trend of ecologically relevant climatic parameters. Black: regression over all stations and year; dark grey: regression over all stations since 1992; light grey: regression for each single weather station with a complete record for at least 15 yr. (a) Days with snow on the ground (snowdays) for 177 stations ( $y=993-0.48 x ; \mathrm{p}<0.001)$. (b) Annual minimum soil temperature (MST) for 146 stations $\left(y=-44+0.02 x_{i} \mathrm{p}<0.001\right)$. (c) Number of freeze/thaw cycles (FTCs) $\left(y=325.9-0.16 x_{;} \mathrm{p}<0.001\right)$ 

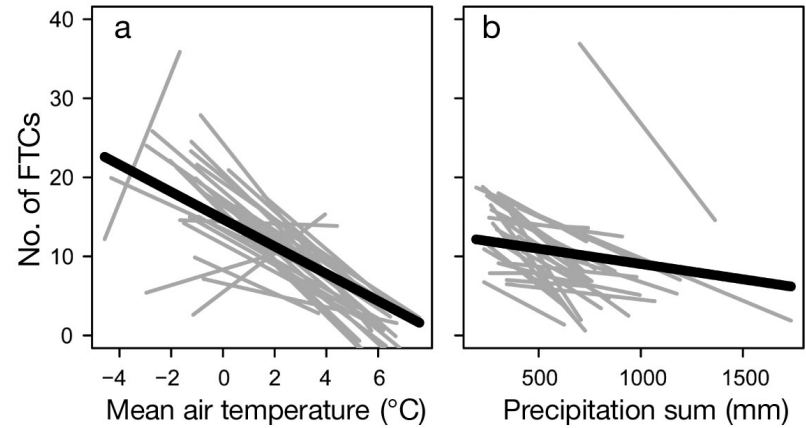

Fig. 2. Least squared regressions of annual soil soil freeze/ thaw cycles (FTCs) at $5 \mathrm{~cm}$ depth against (a) mean air temperature from 1 November to 31 March $(y=14.7-0.172 x ; \mathrm{p}<$ 0.001 ) and (b) total precipitation from 1 November to 31 March $(y=12.9-0.004 x ; p<0.001)$ for the 29 weather stations with a complete record of the relevant climatic parameters at a daily resolution. Grey and black lines as in Fig. 1

a positive trend ( $p<0.05$ for 25 stations) and 28 stations a negative trend ( $p<0.05$ for one station).

The number of FTCs per winter has decreased and the rate of decrease is independent from the start of observations (1950 versus 1992; Fig. 1c). Of the 146 stations, 110 showed a negative trend ( $p<0.05$ for 40 stations) and 36 a positive trend, of which none were statistically significant.

Mean winter air temperature showed a consistent negative correlation with the number of FTCs at almost all stations (26 of 29) analyzed, indicating that warmer winters cause fewer soil FTCs (Fig. 2a). The 3 stations with positive slopes were generally colder and located at altitudes above $700 \mathrm{~m}$ a.s.l. Winter precipitation was without exception negatively correlated with the number of soil FTCs (Fig. 2b).

The significant decrease in the number of FTCs over the last $15 \mathrm{yr}$ occurred predominantly in the eastern central German uplands (Fig. 3). The station with the most rapid change was also the station at the highest

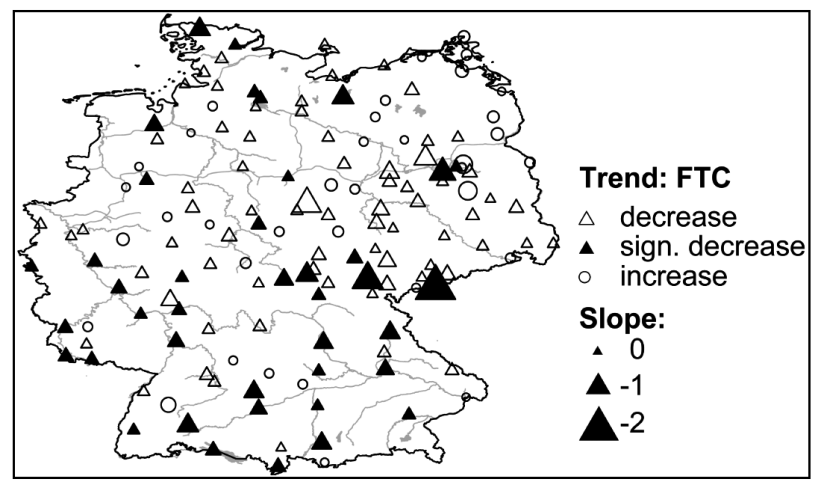

Fig. 3. Trends in the occurrence of soil freeze/thaw cycles (FTCs) for 146 weather stations in Germany. Displayed is the slope of the regression against time for each station. Symbols are filled if $\mathrm{p}<0.05$ elevation (Fichtelberg, 1213 m a.s.l.). Uniform significant reductions in the number of FTCs occurred, furthermore, in southern and western Germany. Fewer significant changes were observed in northeastern and central Germany.

\subsection{Projections}

Snowdays was predicted by 4 climatic and environmental predictors listed in Table 1 (GLM: crossvalidated correlation $\mathrm{r}_{\mathrm{cv}}=0.76$; BRT: $\left.\mathrm{r}_{\mathrm{Cv}}=0.74\right)$. Current spatial patterns are mainly influenced by altitude and temperature, resulting in reduced snow cover in the lowlands of northern Germany (Fig. 4 top panels). Projected future changes imply a more or less uniform reduction in snowdays. The overall mean is predicted to decrease from $33 \mathrm{~d}(1950-2000)$ to $10 \mathrm{~d}$ (2070-2100).

MST was reasonably well predicted by 7 climatic and environmental predictors (Table $1 \mathrm{~K}_{;}$GLM: $\mathrm{r}_{\mathrm{cv}}=0.60$; BRT: $\left.r_{\mathrm{Cv}}=0.60\right)$. Currently, low MSTs occur predominantly in northern Germany, where no long-lasting snow cover exists (Fig. 4 middle panels). Projected future changes imply a stronger increase in MSTs in southern Germany, while changes in the currently colder northern parts are less strong. Nevertheless, MST is predicted to increase over all grid cells from a mean of $-7.5^{\circ} \mathrm{C}(1950-2000)$ to $-2.5^{\circ} \mathrm{C}(2070-2100)$.

Contrary to the other 2 parameters, the number of FTCs could not be well explained by the regression models (GLM: $\mathrm{r}_{\mathrm{cv}}=0.42$; BRT: $\mathrm{r}_{\mathrm{cv}}=0.39$ ). The 2 regression techniques again produced very similar spatial

Table 1. Predictors used in the final generalized linear model regression models; $\mathrm{p}<0.001$, except where otherwise marked. Snowdays: days with snow on ground; MST: minimum soil temperature; FTC: soil freeze/thaw cycle

\begin{tabular}{|llr|}
\hline Target variable & Predictor & \multicolumn{1}{c|}{$t$} \\
\hline Snowdays & Mean annual temperature & -5.9 \\
& Mean annual precipitation & 3.6 \\
& Annual heat moisture index & 0.9 \\
MST & Altitude & 3.8 \\
& Annual heat moisture index & 4.4 \\
& Altitude & 4.4 \\
& Mean diurnal range & -3.8 \\
& Isothermality & 3.5 \\
& Temperature seasonality & $-2.7^{\mathrm{a}}$ \\
& Winter temperature & 5.7 \\
No. of FTCs & Winter precipitation & -3.5 \\
& Mean annual temperature & -6.8 \\
& Mean annual precipitation & 4.4 \\
& Annual heat moisture index & 5.3 \\
& Snowdays & -6.0 \\
a $\mathrm{p}=0.008$ & Temperature seasonality & 5.3 \\
& & \\
\hline
\end{tabular}



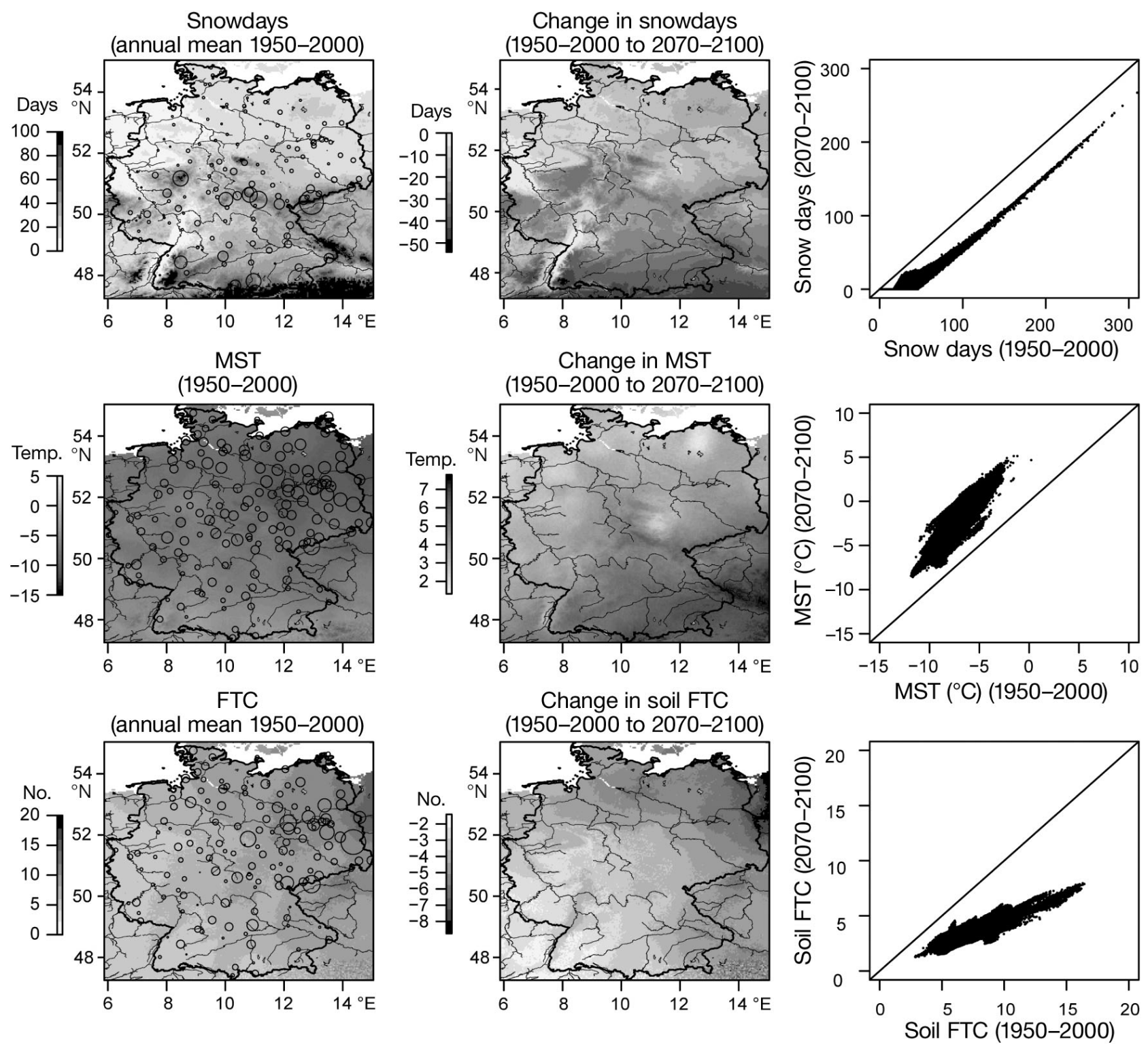

Fig. 4. Current spatial patterns, future changes in snowdays, minimum soil temperature (MST), and number of soil freeze/thaw cycles (FTCs), based on generalized linear models regression between weather station data (circles, with size indicating magnitude) and high resolution climatic parameters (Hijmans et al. 2005)

patterns for current conditions, while differing strongly in future projections. Here, BRT produced results of no overall change, which is not in line with the trends explored above and the GLM results. Even though GLM resulted in reasonable outputs, caution must be exercised in the interpretation of this prediction. The weather station data confirm the general spatial pattern of more FTCs in eastern, southeastern, and northern Germany (Fig. 4 lower panels). For the future, the model forecasts the strongest absolute decrease in areas where most FTCs currently occur. The overall mean is projected to decrease from 7.5 (1950-2000) to 2.9 (2070-2100).

\section{DISCUSSION}

\subsection{Historical trends}

As we predicted, increased air temperatures in Germany over the last 60 yr have coincided with both decreases in the annual number of snowdays, and a decrease in the number of FTCs for the warmest sites; however, our prediction of an opposite trend for the coolest sites was not well supported, as only the coldest of 29 stations showed the expected increase (Fig. 2). In this respect, our results were not consistent with those obtained by Henry (2008) for a range of 
sites across Canada. Nevertheless, with the exception of one site, the Canadian sites fell within a range of -25 to $0^{\circ} \mathrm{C}$, whereas mean annual winter temperatures for most of our sites ranged from 0 to $4^{\circ} \mathrm{C}$. Therefore, our respective studies appear to represent the transition from cold sites, which will experience increased FTCs with warming, and warmer sites, which will feature the opposite trend. This contrast between colder and warmer sites is supported by results obtained for 3 sites along a latitudinal gradient in the United States over the last $40 \mathrm{yr}$ (Sinha \& Cherkauer 2008). The main caution, arising from comparing North American sites to the sites in our study, is that most of the North American sites are strongly influenced by continental air masses, whereas our sites are moderated by the Gulf Stream over winter, causing them to experience milder winters at the same latitudes.

Increased winter precipitation was also correlated significantly with a decreased number of FTCs for our sites, which is consistent with the insulation of soil by snow (Isard \& Schaetzl 1998). However, the influence of variation in precipitation on FTCs was much less than that of temperature. Nevertheless, the decoupling of cold weather from precipitation events could increase the severity of soil freezing. In particular, for our sites, cold dry air masses that move in from the East can result in soil freezing, but are not accompanied by snowfall.

Our spatial analysis of trends in the number of FTCs revealed relatively even coverage of sites exhibiting significant decreases over time. One exception was northeastern Germany, for which temperature records only dated back several decades, reducing the statistical power for these sites. Likewise, sites exhibiting the most extreme slope values tended to feature shorter data series. Another spatial bias in our data arose from the predominant location of weather stations in valleys, leaving the higher elevation regions and especially the Alps under-represented.

Between 1950 and 2009, the observed rate of change in MST in our data set $\left(0.20^{\circ} \mathrm{C}\right.$ per decade) corresponds closely to the warming trend in mean annual air temperature of $0.24^{\circ} \mathrm{C}$ per decade for Germany (DWD 2010). A high share of stations, however, started observations in 1992 (Fig. 1b). Since 1992, MST in our data set increased 3 times faster than mean air temperature $\left(1.24\right.$ versus $0.40^{\circ} \mathrm{C}$ per decade). For Germany, we therefore cannot confirm the expectation of colder soils in a warmer climate despite the decreasing snow cover. For colder temperate regions, however, where this hypthesis was originally formulated (Groffman et al. 2001), this prediction may remain valid.

\subsection{Projections}

Our modelling results, with an increase in the snowfree season and in soil temperatures by the end of the century, agree with other projections for Europe, based on regional climate change models (Jylha et al. 2007, Mellander et al. 2007). However, similar to the analysis of historical data discussed above, models from northern Europe have projected increases in soil FTCs (Venalainen et al. 2001, Mellander et al. 2007), in contrast to our result of decreased FTCs for the German sites, which are warmer.

Combined with our projection of large decreases in snowdays for southern Germany, our model also suggests that MSTs in the south of the country will rise more than in the north. Given that MSTs are already higher in the former than in the latter, the net result is that MSTs may not fall much below $0^{\circ} \mathrm{C}$ in the south by the end of the century, while they will still remain in the range of -5 to $-10^{\circ} \mathrm{C}$ in the north (we discuss the potential ecological consequences of this difference below). Conversely, while the largest number of FTCs is currently observed in northeastern Germany, our model suggests that this region will also experience the greatest reduction in the number of FTCs by the end of the century. However, our modelling results for the number of FTCs were not as reliable as for the other parameters. Generally, our results are biased by a lack of weather stations at high elevation sites. Spatial and temporal projections for the Alps are therefore not as reliable as for the rest of the country, which was well covered by the network of weather stations.

\subsection{Ecological implications}

While reduced snow cover and warmer air temperatures will increase growing season length in Germany, the question remains as to how a decreased number of FTCs and higher MSTs over winter might affect soil and plant processes during the plant growing season. For example, $0^{\circ} \mathrm{C}$, the threshold we use to define FTCs, results in abrupt changes in microbial activity and substrate usage because of decreases in the availability of liquid water (Mikan et al. 2002). However, much colder temperatures are typically required to cause microbial lysis, and microbial growth can continue below freezing (McMahon et al. 2009). Nevertheless, the sub-lethal effects of freezing on soil microorganisms are not well understood; the length of freezing, the number of FTCs, and the rate of freezing can all increase cell damage for a given freezing intensity (Elliott \& Henry 2009, Vestgarden \& Austnes 2009). In addition, for soil microorganisms that survive freezing and desiccation overwinter by accumulating osmolites, thawing can potentially cause 
mortality via osmotic shock, caused by exposure to melted water from snow (Jefferies et al. 2010). Increased microbial activity in warmer soils over winter will also increase respiration, and thus can provide a positive feedback loop for climate warming in arctic (Mikan et al. 2002), boreal (Öquist \& Laudon 2008) and temperate systems (Muhr et al. 2009). Responses of other biogeochemical cycles to warmer soils and fewer FTCs are less clear. For example, although nitrogen (N) mineralization rates can increase with higher microbial activity caused by warming over winter (Clein \& Schimel 1995), the supply of easily-decomposable material might decrease with less root damage (Tierney et al. 2001), and a reduction in soil aggregate disruption (Oztas \& Fayetorbay 2003). Likewise, despite evidence for increased $\mathrm{N}$ leaching losses in response to increased soil frost in some temperate systems (Fitzhugh et al. 2001), the opposite effect has been reported in others (Hentschel et al. 2008). Overall, soil $\mathrm{N}$ retention over winter will depend on plant uptake responses to climate warming (Bilbrough et al. 2000), and microbial or abiotic $\mathrm{N}$ immobilization can also result in a high ecosystem $\mathrm{N}$ retention over winter during periods when plant uptake is low (Steltzer \& Bowman 2005, Judd et al. 2007).

In general, plant responses to winter climate change have been under-represented in the literature relative to soil responses, and data are particularly lacking for temperate systems (Kreyling 2010). Temperate species can incur freezing damage at temperatures in the range of -5 to $-10^{\circ} \mathrm{C}$ (Noshiro \& Sakai 1979), which indicates that MSTs may currently be low enough at our sites to damage overwintering shoot bases and roots, but will not be low enough to do so under a warmer climate in the southern sites. Likewise, physical disruption of roots due to frost heaving and ice formation, which is another important aspect of soil frost, may be reduced or absent in the future at these sites. Changes in the number of FTCs may only have minor effects on plant performance (Steenberg-Larsen et al. 2007); although with climate change, plants may be particularly vulnerable to frost in early spring (Rigby \& Porporato 2008). Changes in the number of FTCs that occur primarily in mid-winter (Fortin 2010), may conversely have little effect on plants that have completed their hardening process by that time. However, there is evidence in arctic systems that reductions in snow cover can leave plant shoots vulnerable to cold air temperatures following mid-winter melts (Bokhorst et al. 2008). Changes in the number of FTCs may also have few effects if frost depth remains unchanged (Campbell et al. 2005). While a sensor depth of $5 \mathrm{~cm}$ in our study provided a useful overall estimate of freezing at a depth where many plant roots and soil microorganisms are present, it underestimated freezing closer to the soil surface, and did not address changes in frost depth.

\section{CONCLUSIONS}

Overall, in contrast to past modelling efforts and analyses of historical data in cold temperate systems, our results suggest that reductions in snow cover as a result of climate warming in Germany - representing a warmer temperate system - will also be accompanied by an increase in MSTs, and a decrease in the number of soil FTCs. Thus, while ecologists have focussed to date on how increased soil freezing with climate warming might affect soil microorganisms and overwintering plants in warmer temperate regions, the consequences of highly reduced soil freezing or even a lack of soil freezing must be considered. Plant responses to decreased soil freezing may not be trivial, since reduced overwinter hardening caused by warming may leave plants more vulnerable to soil frosts when they do occur. Reduced frost may also promote invasion by species from southern regions, including pathogens, herbivores, or competitors.

Acknowledgements. This research was funded by the German Science Foundation (DFG KR 3309/2-1). We thank Doris Scheibe and Reinhold Stahlmann for data preparation.

\section{LITERATURE CITED}

Bilbrough CJ, Welker JM, Bowman WD (2000) Early spring nitrogen uptake by snow-covered plants: a comparison of arctic and alpine plant function under the snowpack. Arct Antarct Alp Res 32:404-411

Bokhorst S, Bjerke JW, Bowles FW, Melillo J, Callaghan TV, Phoenix GK (2008) Impacts of extreme winter warming in the sub-Arctic: growing season responses of dwarf shrub heathland. Glob Change Biol 14:2603-2612

Bolter M, Soethe N, Horn R, Uhlig C (2005) Seasonal development of microbial activity in soils of northern Norway. Pedosphere 15:716-727

> Campbell JL, Mitchell MJ, Groffman PM, Christenson LM, Hardy JP (2005) Winter in northeastern North America: a critical period for ecological processes. Front Ecol Environ 3:314-322

Clein JS, Schimel JP (1995) Microbial activity of tundra and taiga soils at subzero temperatures. Soil Biol Biochem 27: 1231-1234

DWD (Deutscher Wetterdienst) (2010) Mittelwerte der Periode 1961 bis 1990. Accessed 29 October 2010. Available at www.dwd.de/bvbw/appmanager/bvbw/dwdwwwDesktop ?_nfpb=true\&_pageLabel=dwdwww_result_page\&gsbSearch DocId $=675118$

> Elith J, Leathwick JR, Hastie T (2008) A working guide to boosted regression trees. J Anim Ecol 77:802-813

Elliott AC, Henry HAL (2009) Freeze-thaw cycle amplitude and freezing rate effects on extractable nitrogen in a temperate old field soil. Biol Fertil Soils 45:469-476

Ferrick MG, Gatto LW (2005) Quantifying the effect of a freeze-thaw cycle on soil erosion: laboratory experiments. Earth Surf Process Landf 30:1305-1326

Fitzhugh RD, Driscoll CT, Groffman PM, Tierney GL, Fahey TJ, Hardy JP (2001) Effects of soil freezing disturbance on soil solution nitrogen, phosphorus, and carbon chemistry 
in a northern hardwood ecosystem. Biogeochemistry 56: 215-238

Fortin G (2010) Variability and frequency of the freeze thaw cycles in Quebec region, 1977-2006. Can Geogr 54: 196-208

> Groffman PM, Driscoll CT, Fahey TJ, Hardy JP, Fitzhugh RD, Tierney GL (2001) Colder soils in a warmer world: A snow manipulation study in a northern hardwood forest ecosystem. Biogeochemistry 56:135-150

Grogan P, Michelsen A, Ambus P, Jonasson S (2004) Freezethaw regime effects on carbon and nitrogen dynamics in sub-arctic heath tundra mesocosms. Soil Biol Biochem 36:641-654

Henry HAL (2007) Soil freeze-thaw cycle experiments: Trends, methodological weaknesses and suggested improvements. Soil Biol Biochem 39:977-986

Henry HAL (2008) Climate change and soil freezing dynamics: historical trends and projected changes. Clim Change 87:421-434

> Hentschel K, Borken W, Matzner E (2008) Repeated freezethaw events affect leaching losses of nitrogen and dissolved organic matter in a forest soil. J Plant Nutr Soil Sci 171:699-706

> Herrmann A, Witter E (2002) Sources of C and N contributing to the flush in mineralization upon freeze-thaw cycles in soils. Soil Biol Biochem 34:1495-1505

Hijmans RJ, Cameron SE, Parra JL, Jones PG, Jarvis A (2005) Very high resolution interpolated climate surfaces for global land areas. Int J Climatol 25:1965-1978

Isard SA, Schaetzl RJ (1998) Effects of winter weather conditions on soil freezing in southern Michigan. Phys Geogr 19:71-94

Iwata Y, Hayashi M, Suzuki S, Hirota T, Hasegawa S (2010) Effects of snow cover on soil freezing, water movement, and snowmelt infiltration: a paired plot experiment. Water Resour Res 46, W09504, doi:10.1029/2009WR008070

Jarvis A, Reuter HJ, Nelson E, Guevara E (2008) Hole-filled seamless SRTM data version 4. International Center for Tropical Agriculture (CIAT). Available at: http://srtm.csi. cgiar.org

Jefferies RL, Walker NA, Edwards KA, Dainty J (2010) Is the decline of soil microbial biomass in late winter coupled to changes in the physical state of cold soils? Soil Biol Biochem 42:129-135

> Joseph G, Henry HAL (2009) Retention of surface nitrate additions in a temperate old field: implications for atmospheric nitrogen deposition over winter and plant nitrogen availability. Plant Soil 319:209-218

Judd KE, Likens GE, Groffman PM (2007) High nitrate retention during winter in soils of the Hubbard Brook experimental forest. Ecosystems 10:217-225

Jylha K, Fronzek S, Tuomenvirta H, Carter TR, Ruosteenoja K (2007) Changes in frost, snow and Baltic sea ice by the end of the twenty-first century based on climate model projections for Europe. Clim Change 86:441-462

Kreyling J (2010) Winter climate change: a critical factor for temperate vegetation performance. Ecology 91:1939-1948

Kreyling J, Beierkuhnlein C, Pritsch K, Schloter M, Jentsch A (2008) Recurrent soil freeze-thaw cycles enhance grassland productivity. New Phytol 177:938-945

Kreyling J, Beierkuhnlein C, Jentsch A (2010) Effects of soil freeze-thaw cycles differ between experimental plant communities. Basic Appl Ecol 11:65-75

Larsen KS, Ibrom A, Jonasson S, Michelsen A, Beier C (2007) Significance of cold-season respiration and photosynthesis in a subarctic heath ecosystem in northern Sweden. Glob Change Biol 13:1498-1508
Lipson DA, Monson RK (1998) Plant-microbe competition for soil amino acids in the alpine tundra: effects of freezethaw and dry-rewet events. Oecologia 113:406-414

Matzner E, Borken W (2008) Do freeze-thaw events enhance $\mathrm{C}$ and $\mathrm{N}$ losses from soils of different ecosystems? A review. Eur J Soil Sci 59:274-284

McMahon SK, Wallenstein MD, Schimel JP (2009) Microbial growth in Arctic tundra soil at -2 degrees C. Environ Microbiol Rep 1:162-166

Mellander P, Löfvenius MO, Laudon H (2007) Climate change impact on snow and soil temperature in boreal Scots pine stands. Clim Change 85:179-193

Mikan CJ, Schimel JP, Doyle AP (2002) Temperature controls of microbial respiration in arctic tundra soils above and below freezing. Soil Biol Biochem 34:1785-1795

Muhr J, Borken W, Matzner E (2009) Effects of soil frost on soil respiration and its radiocarbon signature in a Norway spruce forest soil. Glob Change Biol 15:782-793

Noshiro M, Sakai A (1979) Freezing resistance of herbaceous plants. Low Temp Sci B Biol Sci 37:11-18

> Öquist MG, Laudon H (2008) Winter soil frost conditions in boreal forests control growing season soil $\mathrm{CO}_{2}$ concentration and its atmospheric exchange. Glob Change Biol 14: 2839-2847

Oztas T, Fayetorbay F (2003) Effect of freezing and thawing processes on soil aggregate stability. Catena 52:1-8

Pinheiro JC, Bates DM (2004) Mixed-effects models in S and S-PLUS. Statistics and Computing. Springer, New York, NY

Randall DA, Wood RA, Bony S, Colman R and others (2007) Climate models and their evaluation. In: Solomon S, Qin D, Manning M, Chen Z, Marquis M (eds) Climate change 2007: the physical science basis: Contribution of Working Group I to the Fourth Assessment Report of the Intergovernmental Panel on Climate Change. Cambridge University Press, Cambridge, p 589-662

Rigby JR, Porporato A (2008) Spring frost risk in a changing climate. Geophys Res Vol 35: L12703

Schaberg PG, Hennon PE, D'Amore DV, Hawley GJ (2008) Influence of simulated snow cover on the cold tolerance and freezing injury of yellow-cedar seedlings. Glob Change Biol 14:1282-1293

Sinha T, Cherkauer KA (2008) Time series analysis of soil freeze and thaw processes in Indiana. J Hydrometeorol 9: 936-950

Steltzer H, Bowman WD (2005) Litter N retention over winter for a low and a high phenolic species in the alpine tundra. Plant Soil 275:361-370

Tierney GL, Fahey TJ, Groffman PM, Hardy JP, Fitzhugh RD, Driscoll CT (2001) Soil freezing alters fine root dynamics in a northern hardwood forest. Biogeochemistry 56: 175-190

Venalainen A, Tuomenvirta H, Heikinheimo M, Kellomaki S, Peltola H, Strandman H, Vaisanen H (2001) Impact of climate change on soil frost under snow cover in a forested landscape. Clim Res 17:63-72

Vestgarden LS, Austnes K (2009) Effects of freeze-thaw on C and $\mathrm{N}$ release from soils below different vegetation in a montane system: a laboratory experiment. Glob Change Biol 15:876-887

> Weih M, Karlsson PS (2002) Low winter soil temperature affects summertime nutrient uptake capacity and growth rate of mountain birch seedlings in the subarctic, Swedish Lapland. Arct Antarct Alp Res 34:434-439

Yanai Y, Toyota K, Okazaki M (2004) Effects of successive soil freeze-thaw cycles on soil microbial biomass and organic matter decomposition potential of soils. Soil Sci Plant Nutr 50:821-829

Submitted: November 4, 2010; Accepted: January 29, 2011 Proofs received from author(s): May 6, 2011 